\title{
The 'SAFE PT' Handover: A Qualitative Study for Developing an Improvised Tool Facilitating Safe Patient Handover
}

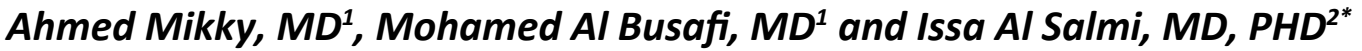 \\ ${ }^{1}$ The Emergency Department, The Royal Hospital, Oman \\ ${ }^{2}$ The Medical Department, The Royal Hospital, Oman \\ *Corresponding author: Issa Al Salmi, MD, BA, FRCPI, MRCP, FRCP, MIPH, PHD, FASN, The Medical Department, Royal \\ Hospital, PO Box 1331, Code 111, Muscat, Oman, Tel: 968-92709000, Fax: 968-245-99966
}

\begin{abstract}
Objectives: The aim of this study is to identify and establish an effective and a standardized tool that is easily reproducible for the safe handover of patients at end of shift at the emergency department (ED) for continuity of care, smooth transition and minimising errors. This tool is designed to assist emergency physician and nurses in building a safe patient culture one that is reliable and upholds the standards of quality and improvement guided by international goals.
\end{abstract}

Methods: To develop this tool; the end users were consulted for understanding the requirements through group discussion, interviews and surveys involving emergency physicians and nurses of different grades. This was further augmented by reviewing literature on international accepted tools. Based on the above information gathered; a tool was developed which was simple, practical and included all necessary details of the patient in an easy and structured format.

Results: Group discussions, interviews and survey conducted showed that current handover practice needed improvement and there was inadequate information being passed on between shifts. This was of concern to most participants and they felt that absence of a reliable tool led to unsafe handovers. The need of the hour was a reliable tool which would standardize and smoothen the handover of patients between shifts in a safe manner. Participants cited examples of leak of information in the current practice which would have changed their approach to patient and having a direct impact on the quality of care delivered. There was also varied responses regarding what was a safe handover practice and prior training received on handover process and the contents of a good handover were found lacking. In order to standardize the handover process based on internationally acclaimed approach and specific to needs as received by end users of the ED, the SAFE PT tool was developed incorporating the relevant details of patient care to facilitate the smooth and safe continuity of care between shifts.

Conclusions: Clinical handover is a high-risk area for patient safety and quality in health care and therefore of high priority for the ED. The SAFE PT tool was derived to emphasize on a culture of patient safety and also for easy recollection of the desired information to be included for a quicker and safer continuity of care between shifts in the ED leading to improved patient satisfaction.

\section{Introduction}

Quality in health care has over the decades moved towards patient safety as one of its primary goals [1]. Safe patients are happy patients! It's important to note continuity of care is crucial to the chain of events of patient in ED where work is divided in 3 to 4 shifts over 24 hours. Therefore, handover between shifts is important for a smooth and quick continuity of care.

The ED is always a busy place sometimes referred to as the most crowded and noisiest service in the whole hospital. The large turnover of patients in ED increases the variability of cases encountered in the ED. The variables are constant over the wide spectrum of the department; ED teams consisting of definite mix of different levels of knowledge, skills and leadership at different shifts.

Morris Gordon [2] concluded in his study that "Whilst undergraduate medical schools recognised handover as an important education issue, they do not feel that

Citation: Mikky A, Al Busafi M, Al Salmi I (2019) The 'SAFE PT' Handover: A Qualitative Study for Developing an Improvised Tool Facilitating Safe Patient Handover. Int J Crit Care Emerg Med 5:082. doi.org/10.23937/2474-3674/1510082

Accepted: July 01, 2019: Published: July 03, 2019

Copyright: (C) 2019 Mikky A, et al. This is an open-access article distributed under the terms of the Creative Commons Attribution License, which permits unrestricted use, distribution, and reproduction in any medium, provided the original author and source are credited. 
they should have the ultimate responsibility for training in this area and as such are responding in varying ways. Undergraduate medical educators should seek to reach consensus as to the extent of provision they will offer. Weaknesses in the literature regarding how to design such education have exacerbated the problem, but the contemporaneous and growing published evidence base should be employed by educators to address this issue".

It is now an accepted norm that clinical handover of patients is a complex process between shifts in an ED and a standard process of handover should be implemented to ensure patient safety. Improvement strategies for clinical handover take time, effort and resources [3]. The same is applicable to transfer of patients all over the hospital.

International researchers have identified a gap in the evidence and practice of handover and called for interventions to standardize it [4]. Lack of a standardized approach to patient handover during shift change could lead to a multitude of problems, missing of vital information of patients which is detrimental to their care, medication errors, adverse events etc. It's equally important to monitor these handovers and have a senior clinician lead to supervise them. These handovers to take place at a dedicated time and in orderly manner.

Good handovers involve a structured process with a well-defined tool involving multi-disciplinary teams lead by a senior clinician and nurse who oversee the flow of patients and can also use their administrative prowess to clear bottlenecks and determine staffing needs of different areas and to mobilize staff with related skills to the areas that would benefit most from it.

A good quality handover is only possible when there is good communication and this is possible by having a structured process with a tool specific to the needs of the ED.

The SAFE PT mnemonic is developed based on best practices and it reminds us that handover is the new age mantra to safety of patients and advocates following it religiously. This paper is a description of the development of the new and improvised tool SAFE PT and its implementation in a structured process of handover during shift changes in the ED.

\section{Literature Review}

Extensive searching was undertaken using electronic databases including websites. Details of the methodology used in the literature review including search terms, inclusion and exclusion criteria are as follows:

The search terms for health-related literature were based on the headings and include any or all of the following terms:

- Continuity of patient care

- Communication and handover
- Patient centred care

- Patient care planning

- Patient care team

- Quality of health care

- Inter-professional relations

- Safety

- Handover

- Shift change

- Clinical information transfer

- Handover practice

- Shift handover

- Tools and handover

- Bedside handover

- $\quad$ Shift briefings

- $\quad$ Shift report

- $\quad$ End of shift reports

- $\quad$ Shift change reports

- Handover practices

- Patient handover

- Team handoffs

\section{Inclusion criteria}

All literature included in the review had the following characteristics. The paper was:

- $\quad$ Published not earlier than 1995

- Written in English

- Related to the search terms

- Based on either qualitative or quantitative data

- A review, research paper or report, guideline, or case study that describes the relationship between handover or communication between shift variables and patient or customer outcomes.

\section{Exclusion criteria}

Papers are not included if they do not provide data that links at least one handover variable (handover variable includes any description where information is transferred between professionals and can include written, verbal, or any other technological form or tool of communication about the patient or patient care) with at least one aspect of patient care outcomes.

Database electronic searching was conducted using the following between the years 1995 until 2015:

- EMBASE

- MEDLINE

- CINAHL

An Internet search via Google using the same search terms was also undertaken.

The topic of clinical handover has taken over mainstream of patient safety and is being widely researched. 
It has been found that it's an area of deep concern and the absence of a robust handover system leads to errors, adverse events, and patient dissatisfaction and in some extreme cases litigation [4]. A survey of trainees in the United State of America (USA) suggested that 15\% of adverse events, errors or near misses involved handover [5].

"Handover of care is one of the most perilous procedures in medicine, and when carried out improperly can be a major contributory factor to subsequent error and harm to patients..." [6].

A survey of Australian doctors revealed that $95 \%$ believed that there were no formal or set procedures for handover [7]. An Australian study of emergency department handover found that in $15.4 \%$ of cases not all required information was transferred, resulting in adverse events [8]. A survey of junior doctors in the United Kingdom (UK) discovered that $83 \%$ believed that the handover process was poor. Written handover was rarely received, accounting for only $6 \%$ of all handovers [9].

The Agency for Health care Research and Quality [10] (AHRQ) published an article in 2013 where they reviewed 17 studies of handovers between paramedical staff and the ED and found loopholes in communication due to the absence of a structured tool. They concluded that a handoff tool could improve handoffs and secure patient transfer.

Earlier to this article the AHRQ [11] had 2 web morbidity \&mortality (M\&M) commentaries and they discussed the problems of not signing out for admitted patients in teaching hospitals. They recommended a standardized approach to be developed for patient safety and believed that a face to face handover supplemented with a written format proved to be an effective method [12]. Good quality care of patient is based on a strong nursing handover process and literature shows poor handovers results in delay in patient care by up to 1 to 2 hours [13].

In 2008, Joint Commission International (JCI) [14] published its requirement for Patient Safety Goal and outlined the salient features to be included in implementing standardized approach to handoff communications.

The World Health Organization (WHO) collaborating centre for Patient Safety [1] outlined the need for handover systems and that the gaps in communication leads to safety risk of patients which could affect continuity of care, mismanagement of case and cause harm to patients.

History of handover originated from the naval services and learning lessons could be adapted from them like the birth of the 'SBAR' $[15,16]$ (Situation, Background, Assessment and Recommendation). Many similar tools have been invented like 'I PASS BATON' [17],'The ABC of Handover'[18],'JUMP'[19] (Jobs outstanding, Unseen patients, Medical contacts, Patients to be aware of), 'ANTICipate'[20] (Administrative data, New information, Tasks, Illness, Contingency planning) etc. The above examples were used to develop a tool specific to Royal Hospital ED with an easy to remember mnemonic for an improved and easier method of handover.

\section{The Royal Hospital Adult ED}

Royal Hospital is a tertiary care teaching hospital, with new attendances of around 50,000 to the adult ED alone and a total hospital capacity of 650 beds. There is a separate Paediatric ED within the hospital.

This study is based in the adult ED, which has a capacity for 14 patients in cubicles, and two waiting areas (one for male and one for female patients).

There is an eight-bed clinical day ward. The 4-bed resuscitation room is set up for critically ill or injured patients; the 'major treatment' area is for those with similar conditions but requiring less intensive observations; and the day ward/observation area is for patients requiring a prolonged period of observation or requiring additional investigations.

The adult ED has round-the-clock consultants or specialists who lead three daily rounds in the adult department at beginning of each shift 07:30, 15:00 and 22:30 hours respectively.

Each shift is led by a specialist who is assigned the overall responsibility of the department. The department is supported by similar nursing complement. ED doctor's handover under the supervision of a consultant during working hours and this task is replicated by specialist during out of working hours. The consultant leads the ward rounds attended by junior doctors and the nursing in-charge.

The Royal Hospital ED has a high load of patients sometimes reaching 200 and above in a day and performance standards in the Royal Hospital mandate workup and diagnosis of patients within 4 hours. The ED being the most volatile service unexpected developments are frequently encountered and it's left to the shift in-charge to fix them as and when the need arises. This is a humongous task and depends heavily on a complete and accurate handover system to start with.

\section{Development of the SAFE PT Handover Tool}

\section{Phase 1: Understanding the current practice}

The current practices of the handovers were observed and to have an in depth understanding of issues faced by end users, group discussions and interviews conducted involving small number of participants at different levels. These brought up certain issues and to have a better understanding of the problems a survey was conducted and about 50 anonymous participants were chosen and were requested to fill out a questionnaire which asked open ended questions and suggestion for 
Box 1: Pearls of interview.

Suggestion derived from interviews:

1. Need for handover tool

2. Dedicated time for handover

3. Need for overlap shift for doctors to avoid delay of patients to be seen during handover time

4. To be led by a senior ED physician and to include the nursing in charge in the handover process.

Box 2: Survey A questionnaire.

1. Education and training of handover prior to working in the ED

2. Whether handover practice was considered adequate to ensure patient safety

3. A section on handover time and format

4. Positive attributes of current practice and issues on its ineffectiveness

5. Participants were asked to enlist 5 patient details they felt had to be included in handover list

6. To give examples of any adverse events encountered due to poor handover any suggestions to improve handover. improvement were sought.

Group discussion: A small group of 10 people were formed and asked for their views about clinical handover, whether they considered it important and what problems they encountered while taking over a shift. The participants all agreed that it was important to have a handover system and that it should be standardized. They felt there was a poor handover system currently and that a lot of relevant information was being missed as it was a verbal handover system and, on few occasions, scribbled onto a paper. The positive feedback given by all participants was that handovers were usually bed-side most of the times. The absence of the whole team rounding was noted and that the new patients to be seen were sometimes delayed if the handover took a long course of time.

Multiple interruptions and distractions during handover were cited. Some junior doctors missed giving important details during verbal handover leading to duplication of work causing wastage of valuable time especially in periods of surge.

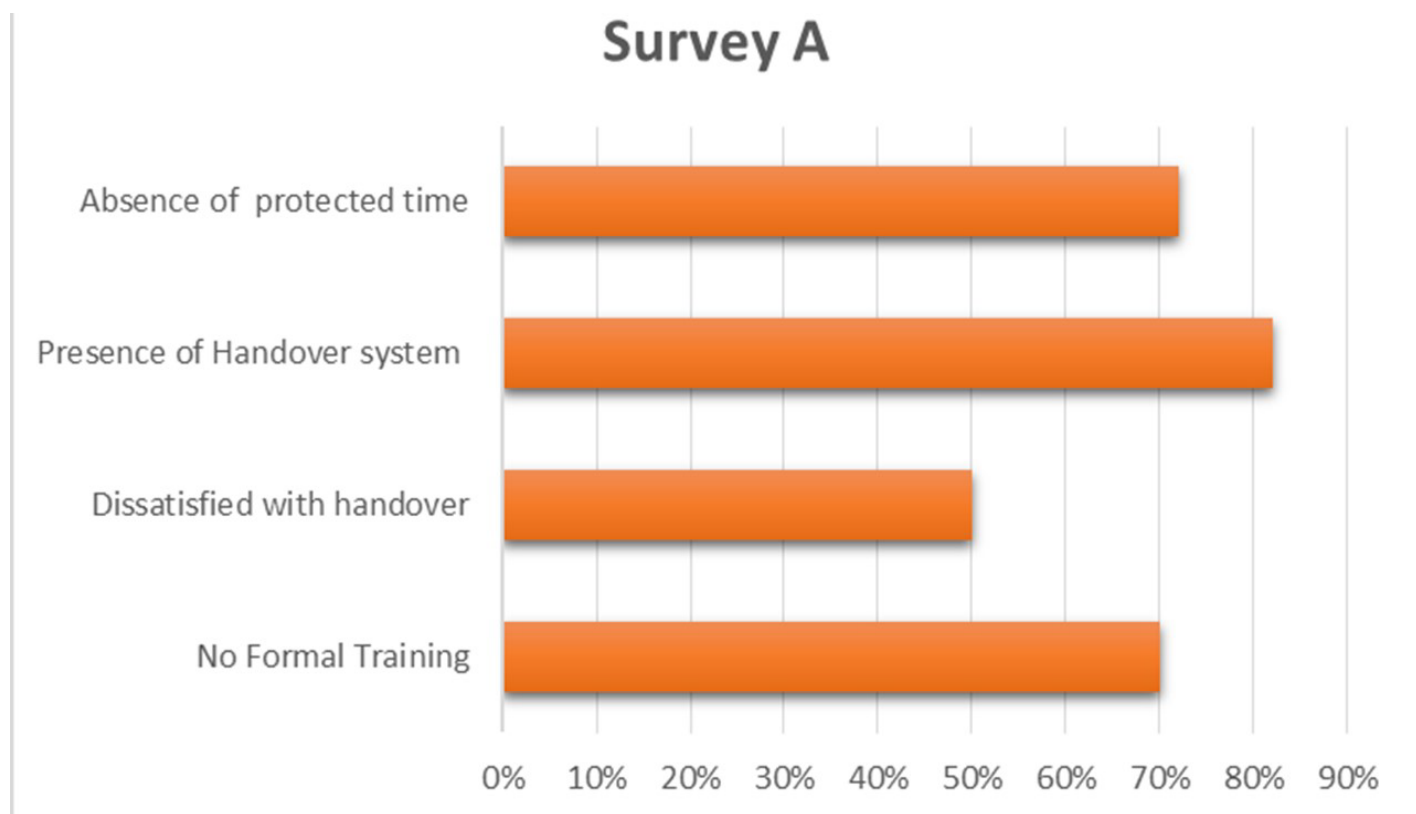

Figure 1: Survey A detailed outcome.

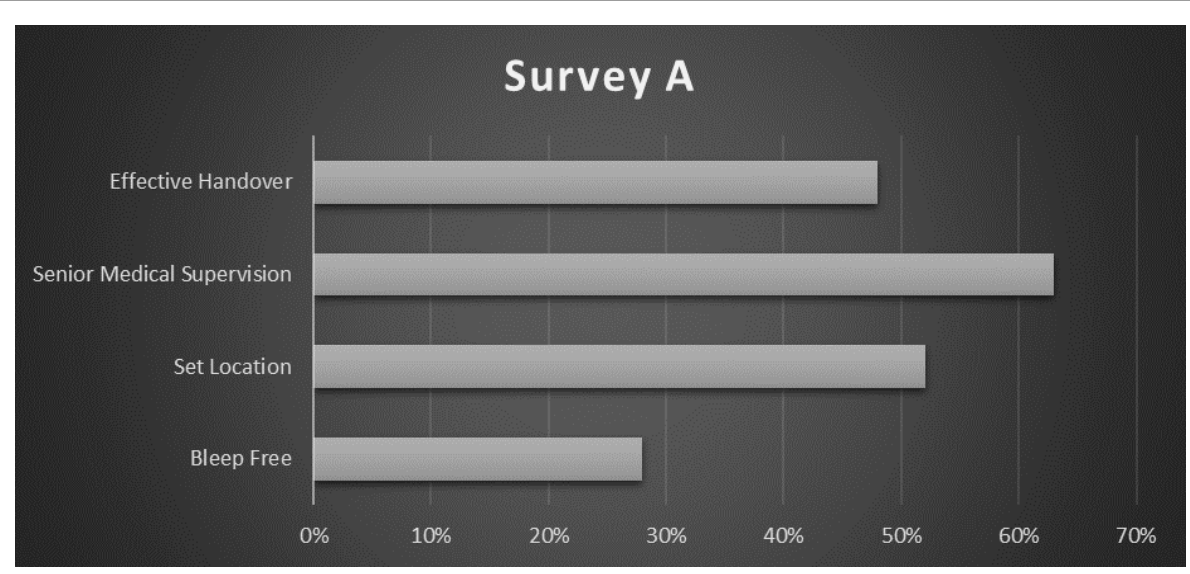

Figure 2: Survey A data analysis. 
Interviews: This included 10 participants involving senior nursing staff, consultants and specialists who were quizzed on what they felt about handover system currently practiced, what they would like to change and suggestions to improve the process. The information collected was then segregated as shown in Box 1.

Survey A: This consisted of a questionnaire and involved 50 participants. The participants were randomly selected from both doctors and nurses at various grades. The questions were aimed at current practices as shown in Box 2.

As shown in Figure 1, most participants deemed that no formal training was received at medical school with regards to handover. Half of the participants said they were dissatisfied with the handover process. $82 \%$ agreed that there was some kind of handover system and $72 \%$ believed that the time of handover was not protected. As shown in Figure 2, 95\% said the current handover system was bedside verbal format and that bedside handover was considered as an effective component of a handover system. Half of them believed that the handover style needed to be changed as it was ineffective.

The points listed by most of them on what had to be included in the handover, most of them believed that patient history, haemodynamic status, provisional diagnosis, investigations, medications received, and disposition plan were mandatory to patient handover.

The examples of adverse events or ineffective handover ranged from wrong medication, repetition of imaging studies, miscommunication and loss of vital

Box 3: Handover format.

Participants suggested the following points to improve the handover:

1. Verbal and handover written format

2. Well-structured format

3. Multi-disciplinary team handover

4. Protected time for handover

5. Monitoring of new system once implemented

6. Disposition plan to be included

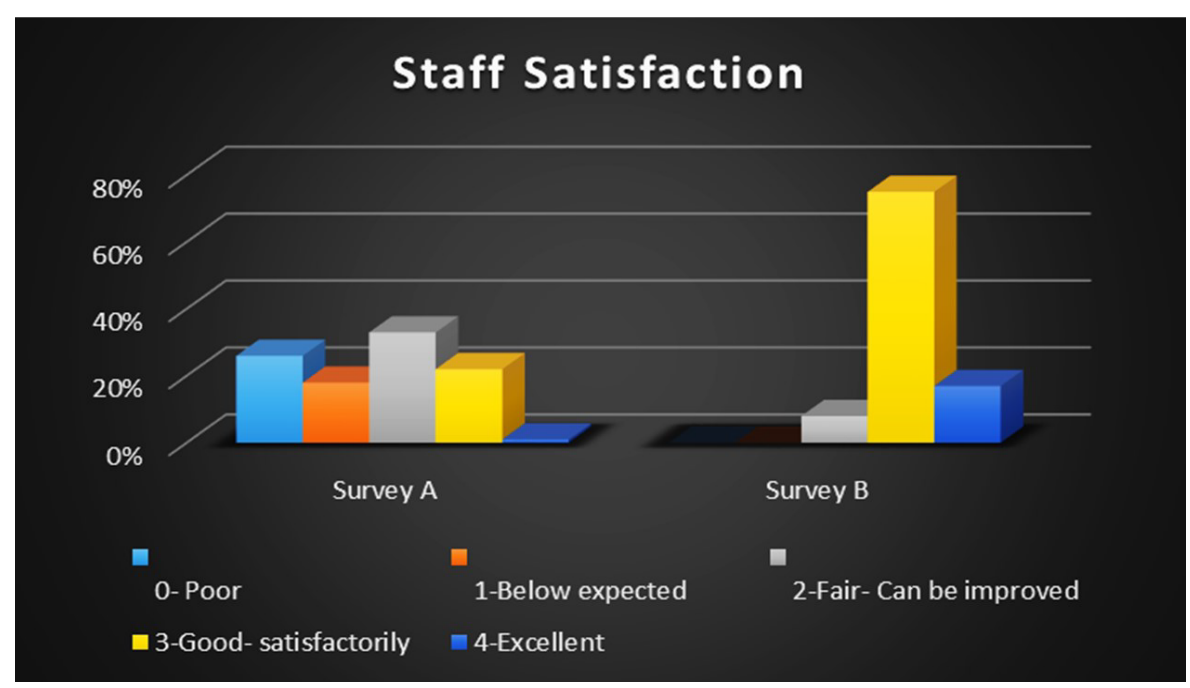

Figure 3: Staff satisfaction comparison between survey A \& B.

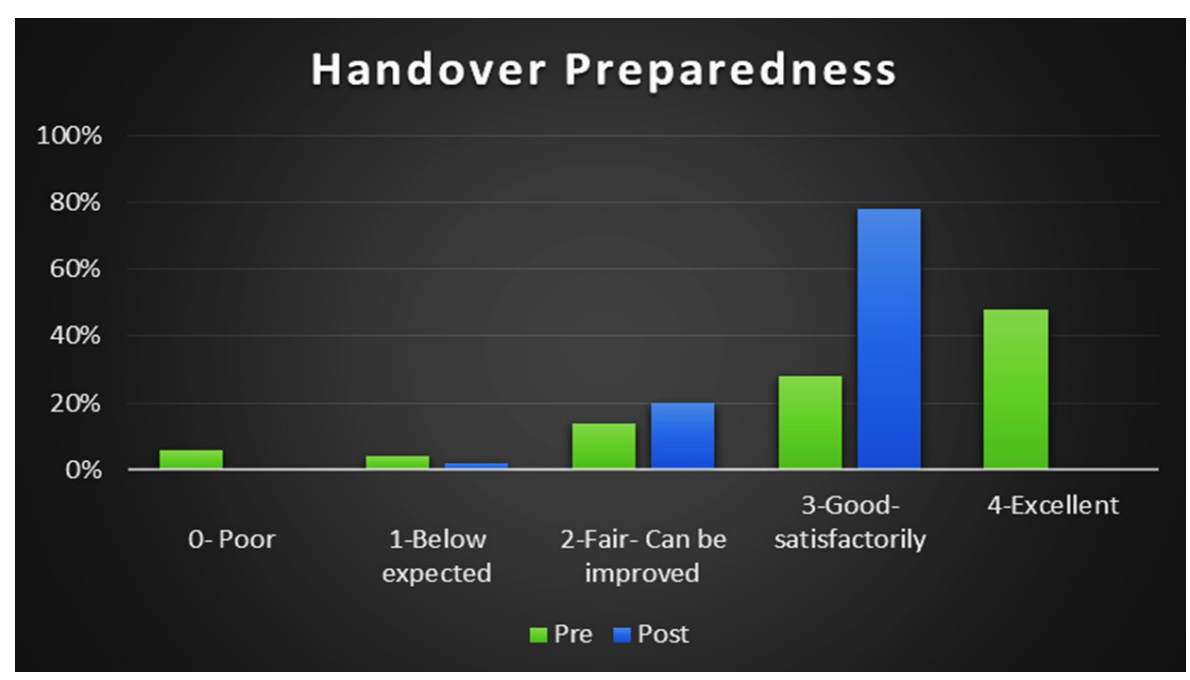

Figure 4: Comparison of handover preparedness between survey A \& B. 
information leading to poor handover of patients and compromising patient safety.

Almost all (99\%) of them agreed that clinical handover was key to patient safety and leading to a high quality of care of patients. The suggestions to improve handover by majority of participants are listed in Box 3 .

\section{Phase 2}

This was a period of 3 months which included awareness of handover amongst the ED physicians and nurses and weekly training schedules for staff on safe handover practices. This included the implementation of the tool and staff empowered to utilise it. At the end of 3 months survey $B$ was conducted similar to the first to look for changes and any improvement noticed by the end users after introduction of the new tool and if there were any difficulties with it, as shown in Figure 3.

Figure 4 shows the comparison of handover preparedness between survey $A$ and $B$. The findings of survey $B$ with regards to the training and awareness program for clinical handover towards patient safety, was believed to be effective. More than $90 \%$ of participants said that they were prepared adequately for an efficient and safe handover system. 99\% agreed that formal teaching made a difference.

$80 \%$ of them believed that this had an impact on

Box 4: Handover tool format.

The surveyed staff highlighted the limitation of the handover tool:

1. Time consuming to fill out the form for handover

2. To reduce the number of columns to be filled on the handover sheet

3. Request for an electronic assistance for quicker filling of form

4. Time of arrival of patient to be omitted from the handover sheet

5. Use of printed stickers for patient identification patient satisfaction. $96 \%$ believed that there was a reduction in medical errors. $82 \%$ believed the new system was user friendly. All agreed that there was adequate senior supervision, $99 \%$ believed it to be an effective handover, about $80 \%$ believed that it was not protected (bleep free) time. 98\% believed that it improved the length of stay (LOS) at ED. The limitation of the new handover tool as listed in Box 4 and suggestions in Box 5.

At the end of phase 2, the handover tool was redesigned, and suggestions incorporated the final SAFE PT tool was formatted and illustrated below in Figure 5 .

This tool utilized the Mnemonic SAFE PT to include all the relevant details for the patient with priority to the red flags and those that warranted immediate attention.

\section{S - Situation patient ID, Background of patient}

A - Assessment chief complaints, Provisional diagnosis, Action taken

F - Follow up recommendations, referrals

E - Events, Red flags

$P$ - Pending labs/procedures

$\mathrm{T}$ - Teams outgoing and incoming

Similar form was designed for nurses with the minor addition of medication, allergy in place of provisional diagnosis and action taken under assessment.

Box 5: Improvised handover tool.

The suggestions for improvised handover:

\section{Red flags}

2. Identifying both handover teams

3. Dedicated time and space

4. Electronic support

5. Minimize interruptions

6. Overlapping shift for new patients to be seen immediately during handover time

7. Compliance of the new system to be monitored with constructive feedback on regular monthly basis.

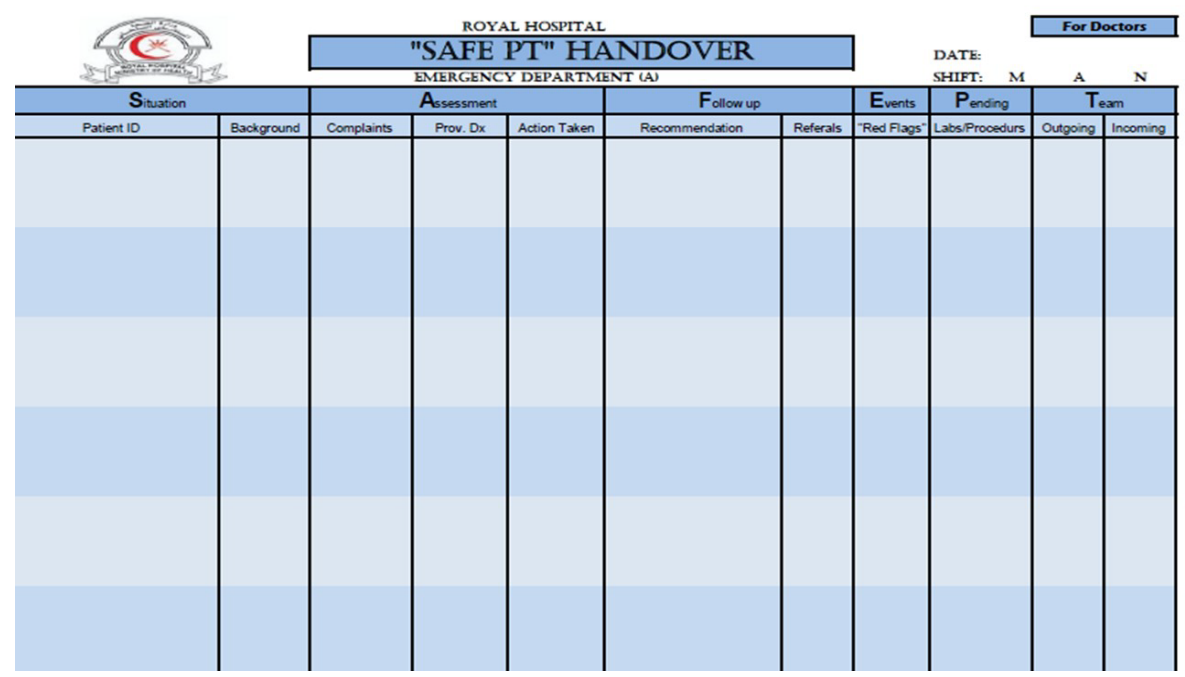

Figure 5: The SAFE PT Handover. 
Trend of Length of Stay of patients in ED $>4$ hours

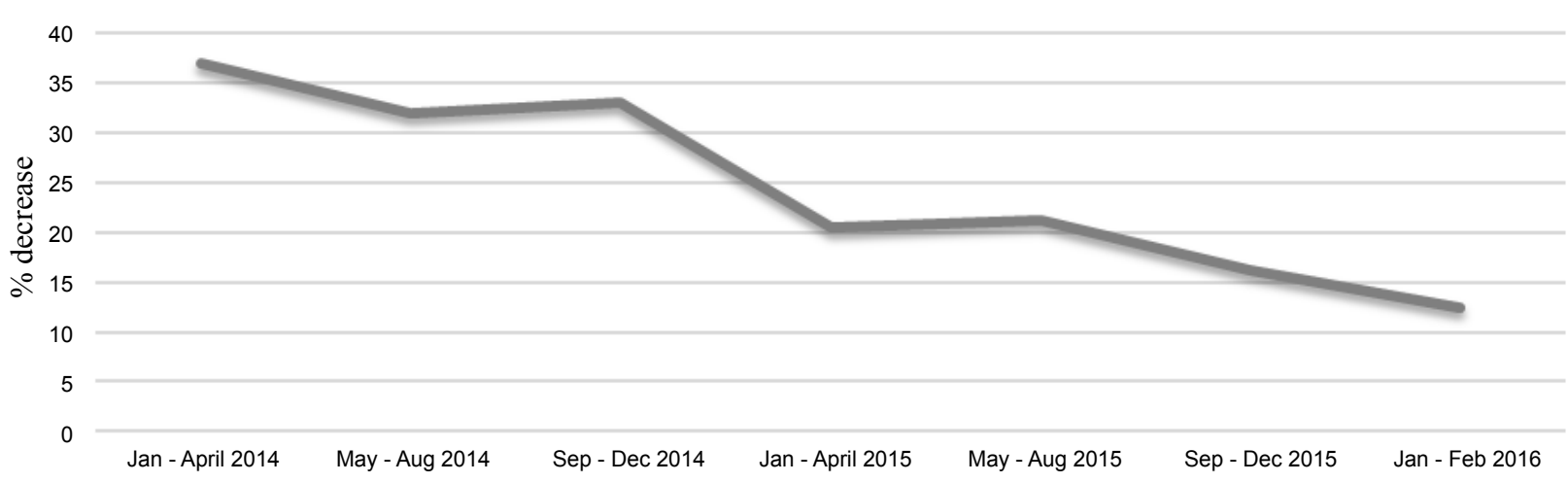

Figure 6: Trend of length of stay of patient in ED > 4 hours; KPI Adult ED [21].

Table 1: In this data set, its improved preparedness on average, by 0.66 points.

\begin{tabular}{l|l|l|l|l|l|}
\multicolumn{1}{l}{ Paired Samples Statistics } & Mean & N & Std. Deviation & Std. Error Mean \\
\hline \multirow{2}{*}{ Pair 1} & Post & 4.6200 & 50 & 0.49031 & 0.06934 \\
\cline { 2 - 7 } & Pre & 3.9600 & 50 & 0.34759 & 0.04916 \\
\hline
\end{tabular}

\section{Paired Samples Test}

\begin{tabular}{|c|c|c|c|c|c|c|c|c|c|}
\hline & & \multicolumn{5}{|c|}{ Paired Differences } & \multirow[t]{3}{*}{$\mathrm{t}$} & \multirow[t]{3}{*}{ df } & \multirow{3}{*}{$\begin{array}{l}\text { Sig. } \\
\text { (2-tailed) }\end{array}$} \\
\hline & & \multirow[t]{2}{*}{ Mean } & \multirow[t]{2}{*}{$\begin{array}{l}\text { Std. } \\
\text { Deviation }\end{array}$} & \multirow[t]{2}{*}{$\begin{array}{l}\text { Std. Error } \\
\text { Mean }\end{array}$} & \multicolumn{2}{|c|}{$\begin{array}{l}95 \% \text { Confidence Interval of } \\
\text { the Difference }\end{array}$} & & & \\
\hline & & & & & Lower & Upper & & & \\
\hline Pair 1 & Post - Pre & 0.66000 & 0.47852 & 0.06767 & 0.52401 & 0.79599 & 9.753 & 49 & 0.000 \\
\hline
\end{tabular}

\section{Phase 3}

The final format of the SAFE PT was implemented for a period of 6 months with dedicated time and introduction of an overlapping shift. The compliance was closely monitored, and more than $95 \%$ compliance rate was found at end of 6 months following the process of safe patient handover. The LOS was found to have improved as shown in Figure 6.

Figure 6 shows the trend of length of stay of patient in ED > 4 hours; KPI of adult ED [21].

ED reported a considerable decline in the length of stay of their patients beyond 4 hours of their arrival in the ED. A major contributor to this improvement was due to the remarkable changes that the SAFE PT Handover system brought with it improving patient satisfaction to a large extent.

\section{Data Analysis}

Data collected from nursing department about pre and post preparedness of safe handover model are exported to SPSS version 20 Paired t test is applied to test whether there is significant difference in preparation of department with regard to pre and post implementation of safe handover model.

$\mathrm{HO}$ : There is no difference in mean preparedness with regard to pre and post safe handover module. ( $\mathrm{HO}=$ Hypothesis 0$). \mathrm{H} 1$ : There is a difference in mean preparedness with regard to pre and post safe handover module. $(\mathrm{H} 1=$ Hypothesis 1$)$ Table 1.

There is strong evidence $(t=9.73, p=0.000)$ that the department were prepared for safe handover. In this data set, its improved preparedness on average, by 0.66 points. The null hypothesis is rejected, since $p<0.05$ (in fact $p=0.000)$.

Therefore, there is a difference in mean preparedness of department post safe handover practice in positive way.

Figure 7 shows the results from nursing staff about pre and post preparedness of safe handover.

Data collected from ED physicians about pre and post preparedness of safe handover model are exported to SPSS version 20. Paired t test is applied to test whether there is significant difference in preparation of doctors with regard to pre and post implementation of safe handover model.

$\mathrm{HO}$ : There is no difference in mean preparedness of doctors with regard to pre and post safe handover module. $\mathrm{H} 1$ : There is a difference in mean preparedness of doctors with regard to pre and post safe handover module. Figure 8 shows the results from ED physicians about pre and post preparedness of safe handover Table 2.

There is strong evidence $(t=8.22, p=0.000)$ that 


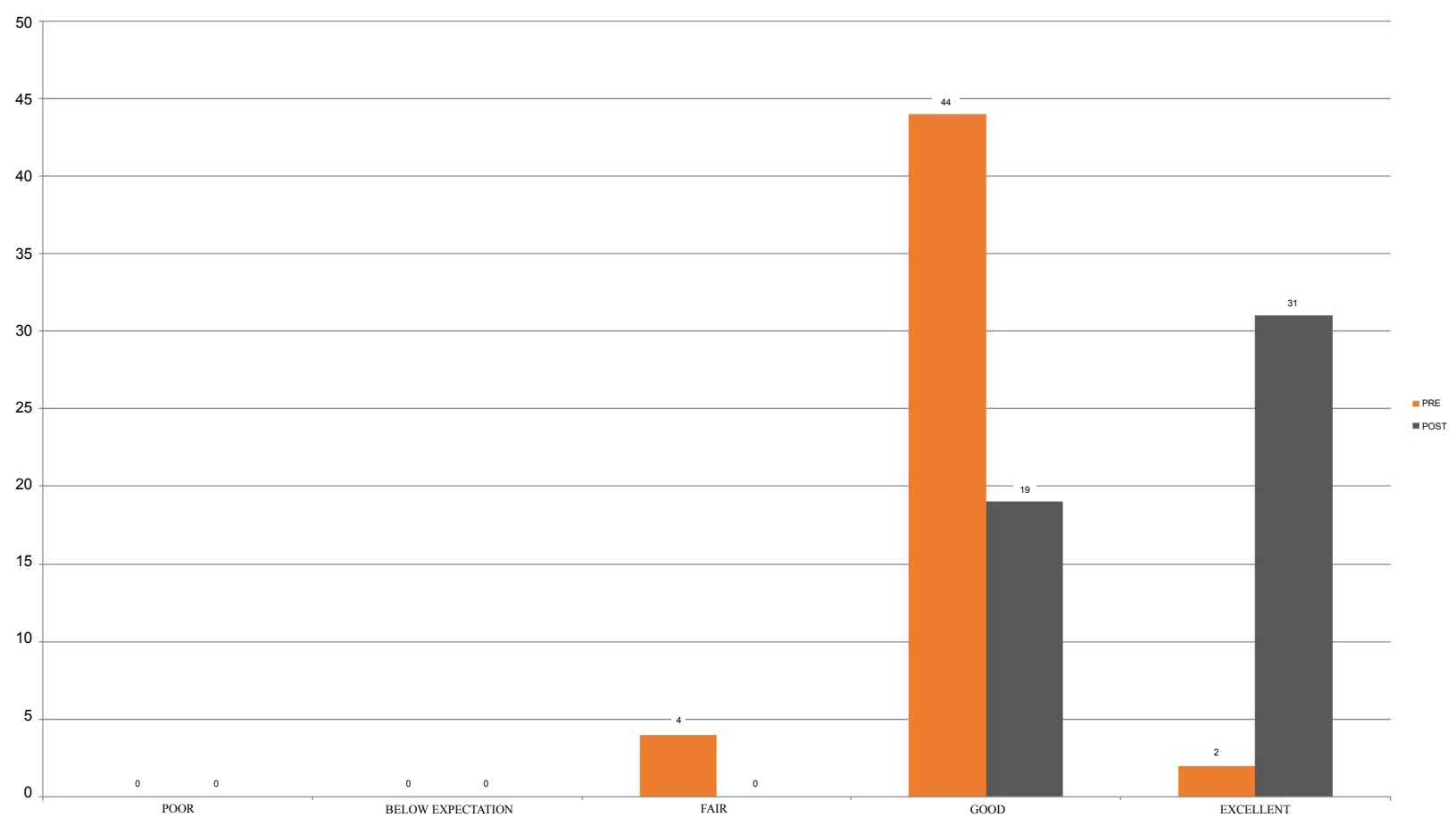

Figure 7: Results from nursing staff about pre and post preparedness of safe handover.

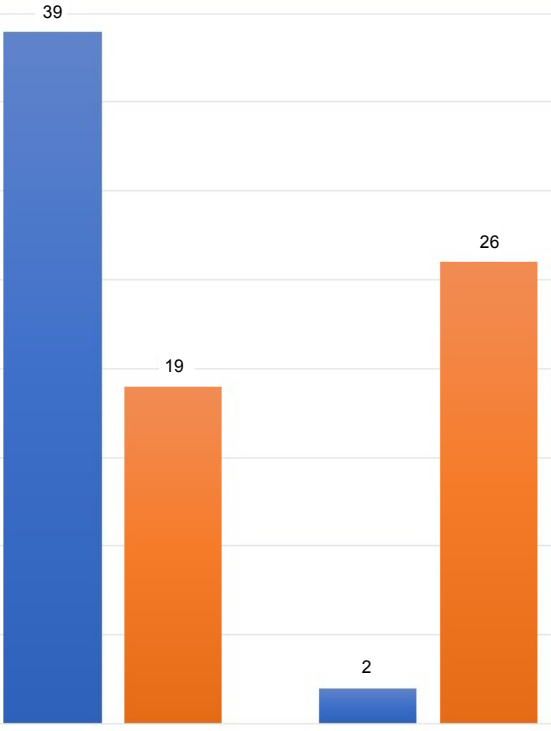

GOOD

EXCELLENT

Figure 8: Results from ED physicians about pre and post preparedness of safe handover.

the doctors were prepared for safe handover. In this data set, it improved preparedness on average, by 0.58 points. The null hypothesis is rejected, since $p<0.05$ (in fact $p=0.000$ ). Therefore, there is a difference in mean preparedness of doctors post safe handover practice in positive way.

Data collected from ED nurses about pre and post preparedness of safe handover model are exported to SPSS version 20. Paired $t$ test is applied to test whether there is significant difference in patient satisfaction with regard to pre and post implementation of safe handover model, as shown in Figure 9.

$\mathrm{HO}$ : There is no difference in mean satisfaction of patient with regard to pre and post safe handover module. H1: There is a difference in mean satisfaction of patient with regard to pre and post safe handover module Table 3.

There is strong evidence $(t=4.41, p=0.000)$ that there is improvement in patient satisfaction post implementation of safe handover model. In this data set, its improved patient care on average, by 0.32 . The null 
Table 2: In this data set, it improved preparedness on average, by 0.58 points.

\section{Paired Samples Statistics}

\begin{tabular}{|l|l|l|l|l|l|}
\hline \multicolumn{2}{|c|}{} & Mean & N & Std. Deviation & Std. Error Mean \\
\hline Pair 1 & Post & 4.4200 & 50 & 0.67279 & 0.09515 \\
\cline { 2 - 6 } & Pre & 3.8400 & 50 & 0.50950 & 0.07205 \\
\hline
\end{tabular}

\section{Paired Samples Test}

\begin{tabular}{|c|c|c|c|c|c|c|c|c|c|}
\hline & & \multicolumn{5}{|c|}{ Paired Differences } & \multirow[t]{3}{*}{$t$} & \multirow[t]{3}{*}{ df } & \multirow{3}{*}{$\begin{array}{l}\text { Sig. } \\
\text { (2-tailed) }\end{array}$} \\
\hline & & \multirow[t]{2}{*}{ Mean } & \multirow[t]{2}{*}{$\begin{array}{l}\text { Std. } \\
\text { Deviation }\end{array}$} & \multirow[t]{2}{*}{$\begin{array}{l}\text { Std. Error } \\
\text { Mean }\end{array}$} & \multicolumn{2}{|c|}{$\begin{array}{l}95 \% \text { Confidence Interval of } \\
\text { the Difference }\end{array}$} & & & \\
\hline & & & & & Lower & Upper & & & \\
\hline Pair 1 & Post - Pre & 0.58000 & 0.49857 & 0.07051 & 0.43831 & 0.72169 & 8.226 & 49 & 0.000 \\
\hline
\end{tabular}

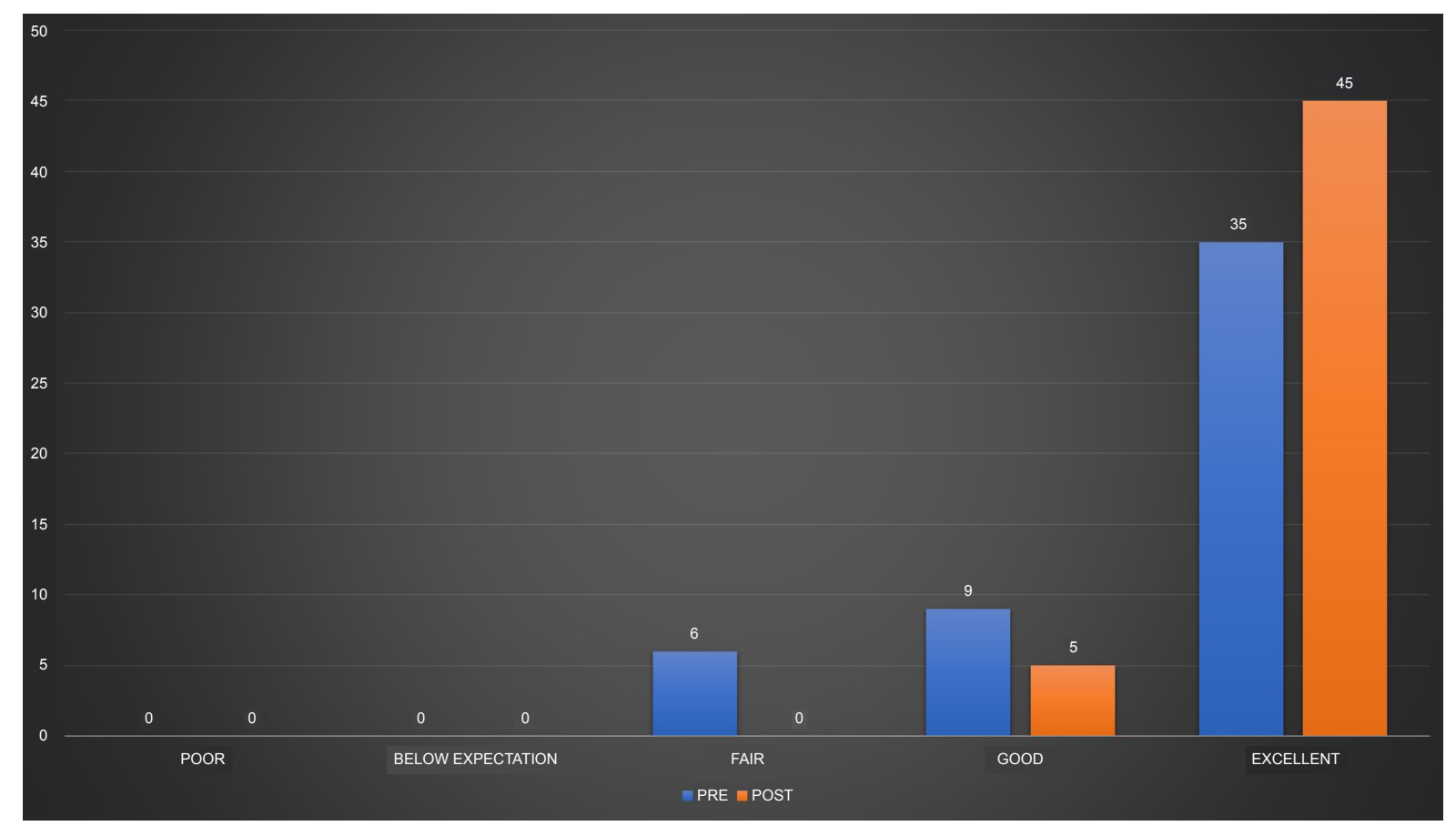

Figure 9: Paired t test is applied to test whether there is significant difference in patient satisfaction with regard to pre and post implementation of safe handover model.

Table 3: In this data set, its improved patient care on average, by 0.32 points.

\section{Paired Samples Statistics}

\begin{tabular}{|l|l|l|l|l|l|}
\hline \multicolumn{2}{|l|}{} & Mean & N & Std. Deviation & Std. Error Mean \\
\hline Pair 1 & Post & 4.9000 & 50 & 0.30305 & 0.04286 \\
\cline { 2 - 6 } & Pre & 4.5800 & 50 & 0.70247 & 0.09934 \\
\hline
\end{tabular}

\section{Paired Samples Test}

\begin{tabular}{|c|c|c|c|c|c|c|c|c|c|}
\hline & & \multicolumn{5}{|c|}{ Paired Differences } & \multirow[t]{3}{*}{$\mathrm{t}$} & \multirow[t]{3}{*}{ df } & \multirow{3}{*}{$\begin{array}{l}\text { Sig. } \\
\text { (2-tailed) }\end{array}$} \\
\hline & & \multirow[t]{2}{*}{ Mean } & \multirow[t]{2}{*}{ Std. Deviation } & \multirow[t]{2}{*}{$\begin{array}{l}\text { Std. Error } \\
\text { Mean }\end{array}$} & \multicolumn{2}{|c|}{$\begin{array}{l}95 \% \text { Confidence Interval of } \\
\text { the Difference }\end{array}$} & & & \\
\hline & & & & & Lower & Upper & & & \\
\hline Pair 1 & Post - Pre & 0.32000 & 0.51270 & 0.07251 & 0.17429 & 0.46571 & 4.413 & 49 & 0.000 \\
\hline
\end{tabular}

hypothesis is rejected, since $p<0.05$ (in fact $p=0.000$ ). Therefore, there is a difference in mean satisfaction of patient post safe handover practice in positive way.

\section{Discussion}

The handover of patients in the Royal Hospital adult
ED was improvised with the introduction of a structured format of SAFE PT tool. This was widely accepted, and feedback was collected to confirm its effectiveness.

There were few limitations to this study, the participants were aware of the study being conducted and 
leading to a bias especially in the group discussion and interviews. This bias was eliminated by the surveys conducted anonymously. The handover system is conducted to minimize risk and to improve patient satisfaction. But unfortunately, it was beyond the scope of this study to advance to next level of including patient participation in the handover system.

SAFE PT handover served the purpose of having a structured approach to handover of patients between shifts in the busy emergency department and to minimize risk of patient safety. The system brought about a cultural change in the management of patients and was welcomed by both clinicians and nurses equally as it made the process easier and quickened the continuity of care having a positive impact on patient flow and reducing the length of stay of patients. It was found to directly improve patient satisfaction. Most patients could identify that the handover was led by a senior physician and that he/she prioritized the needs of patient based on their acuity and there was no delay of patients during handover time with the introduction of the overlap shift to serve this purpose.

This handover was applied to the nurses simultaneously with inclusion of allergies in the handover format and found to be as effective and popular as it was with the physicians. The impact of SAFE PT tool is further studied in the subsequent paper.

\section{Acknowledgements}

The authors would like to thank all the staff at the emergency department at Royal Hospital facilitating this research, and extend special thanks to Dr. Sheeba Jabir, Dr.Spateeka Prakash for their assistance in the 'SAFE PT' handover, and to Professor Kevin Mackway-jones (Manchester Metropolitan University) for his support and expertise advice.

\section{Conflict of Interest and Funding}

The author has not received any funding or benefits from industry or elsewhere to conduct this study. We would like to seek reduction or waiver of charges.

\section{Compliance Statement}

Authors confirm compliance with animal/human ethics guidelines. The ethical clearance for the study was approved by the Medical Ethics and Scientific Research Committee at the Royal Hospital with an approval number MESRC 48/2006.

\section{References}

1. WHO Collaborating Centre for patient Safety Solutions (2007) Communication during Patient Hand-Overs. Patient Safety, 1.

2. Morris $G$ (2013) Training on handover of patient care within UK medical schools. Medical Education Online 18: 1-5.

3. Dorothy J (2010) OSSIE guide to clinical handover improvement. Australian Commission on Safety and Quality in Health Care, 56.

4. Wong MC, Yee KC, Turner P (2008) Clinical handover literature review. eHealth services research group, University of Tasmania, Australia, 1-114.

5. Jagsi R, Kitch B, Weinstein D, Campbell E, Hutter M, et al. (2005) Residents report on adverse events and their causes. Arch Intern Med 165: 2607-2613.

6. (2011) Professor Sir John Lilleyman, Medical Director, National Patient Safety Agency, UK.

7. Bomba DT, Prakash R (2005) A description of handover processes in an Australian public Hospital. Aust Health Rev 29: 68-79.

8. Ye K, Taylor DM, Knott JC, Dent A, MacBean CE (2007) Handover in the emergency department: Deficiencies and adverse effects. Emer Med Australas 19: 433-441.

9. Roughton VJ, Severs MP (1996) The junior doctor handover: Current practices and future expectations. J R Coll Physicians Lond 30: 213-214.

10. Dowson S, King L, Grantham H (2013) Review article: Improving the hospital clinical handover between paramedics and emergency department staff in the deteriorating patient. Emerg Med Australas 25: 393-405.

11. Christopher F (2009) Cases \& Commentaries. Patient Safety Network (PSNet).

12. Pothier D, Monteiro P, Mooktiar M, Shaw A (2005) Pilot study to show the loss of important data in nursing handover. Br J Nur 14: 1090-1093.

13. Hansten R (2003) Streamline change of shift report. Nurs Manage 34: 58-59.

14. Joint Commission International (2008) Improving America's hospitals: The joint commission's annual report on quality and safety.

15. Pope BB, Rodzen L, Spross G (2008) Raising the SBAR: How better communication improves patient outcomes. Nursing 38: 41-43.

16. Thomas CM, Bertram E, Johnson D (2009) The SBAR communication technique: Teaching nursing students professional communication skills.. Nurse Educ 34: 176180.

17. Pamela $T$ (2012) Implementation of TeamSTEPPS in the emergency department. Crit Care Nurs Q 35: 208-212.

18. Farhan M, Brown R, Woloshynowych M, Vincent C (2012) The $A B C$ of handover: A qualitative study to develop a new tool for handover in the emergency department. Emergency Medicine Journal 29: 941-946.

19. McCann L, McHardy K, Child S (2007) Passing the buck: Clinical handovers at a tertiary hospital. N Z Med J 120: 2778.

20. Vidyarthi AR, Arora V, Schnipper JL, Wall SD, Wachter RM (2006) Managing discontinuity in academic medical centers: Strategies for a safe and effective resident signout. J Hosp Med 1: 257-266.

21. KPI Adult ED (2015) Reported by the quality team adult emergency department, The Royal Hospital, Muscat, Sultanate of Oman, Oman.

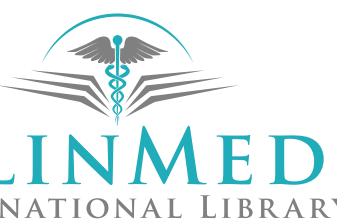

